\title{
Glucose tolerance and insulin sensitivity in malnourished children
}

\author{
By G. A. O. ALLEYNE, P. M. TRUST, H. FLORES \\ AND H. ROBINSON \\ Tropical Metabolism Research Unit, University of the West Indies, \\ Mona, Kingston 7 , Famaica, WI \\ (Received 28 September 1971 - Accepted 19 November 1971)
}

\begin{abstract}
I. In malnourished, compared with recovered children, fasting blood glucose concentrations were low and there was impaired peripheral glycolysis as shown by a failure of blood lactate to rise after glucose was injected intravenously.

2. Homogenates of muscle biopsies from malnourished and recovered children produced equal amounts of lactate when incubated anaerobically with various substrates, but when compared with homogenates of biopsies from normal children the pattern suggested an impairment of glycolysis.

3. The rate of glucose disappearance after intravenous glucose was slow in the malnourished child and there was possibly diminished sensitivity to exogenous insulin.

4. Isocaloric diets relatively high or low in fat were fed to children who had recovered from malnutrition. Glucose tolerance, insulin sensitivity, fasting plasma insulin and insulin response to intravenous glucose were all the same in children on either diet.
\end{abstract}

There have now been several studies which show that glucose tolerance is impaired in malnourished infants (Sloane, Taitz \& Gilchrist, r961; Baig \& Edozien, 1965; Hadden, r967; James \& Coore, 1970; Milner, 1971), and Baig \& Edozien (1965) among others showed that glucose intolerance was associated with low levels of plasma insulin. This glucose intolerance may persist for many years after apparent clinical recovery (Cook, I967), and James \& Coore (1970) also point out that the insulin response to intravenous glucose is still impaired when children who have clinically recovered are compared with ones who have never been malnourished.

The present studies represent an attempt to determine the importance of insulin insensitivity as a contributing factor in glucose intolerance, and to correlate clinical and in vitro studies. In addition, the effect of diet on glucose tolerance and insulin release was assessed in children who had recovered from malnutrition.

\section{EXPERIMENTAL}

Patients and treatment. The children studied suffered from primary protein-calorie malnutrition and the typical picture as seen in our Unit has been described in detail previously (Waterlow, Cravioto \& Stephen, r960; Alleyne, 1970). They were all admitted to the metabolic ward of the Medical Research Council's Tropical Metabolism Research Unit and treated with graduated milk feeds, vitamin and mineral supplements until they had reached weight expected for their height. (The ideal weight for height was calculated from the $5^{\text {oth }}$ percentile of the Boston Standards (Nelson, 1959).) 
Table I. Percentage of total calories derived from protein, fat and carbohydrate, and energy values of the high-fat and low-fat diets given to the children

$\begin{array}{lcc} & \text { High-fat } & \text { Low-fat } \\ \text { Protein } & 9 & \text { II } \\ \text { Fat } & 58 & 25 \\ \text { Carbohydrate } & 33 & 64 \\ \text { Energy value } & & \\ \quad \mathrm{kcal} / 1 & \mathrm{I} 350 & \mathbf{1 1 6 2} \\ \mathrm{kJ} / 1 & 5648 & 4862\end{array}$

All children were fasted for $6-8 \mathrm{~h}$ and studies were begun between 08.00 and 09.00 hours.

Glucose tolerance tests. Glucose $(0.4 \mathrm{~g} / \mathrm{kg}$ body-weight) was given intravenously and blood samples were taken by venepuncture 15,30 and 60 min later for measurement of lactate, pyruvate and glucose.

\section{Lactate production by muscle homogenates in vitro}

The method used was adapted from that described by Layzer, Rowland \& Ranney (1967). In the malnourished and recovered children, muscle biopsies were performed with the Baylor necdle as described by Nichols, Hazlewood \& Barnes (1968). A sample of muscle approximately $20-30 \mathrm{mg}$ was obtained, trimmed of excess fat, weighed and homogenized by hand in 100 volumes of ice-cold to mmol-potassium phosphate buffer $\mathrm{pH} 7 \cdot 6$. For control normal children, samples of rectus abdominis were obtained when elective surgery was being performed in healthy children for repair of umbilical hernias. Samples $\left(25^{\circ} \mu \mathrm{l}\right)$ of the homogenate were incubated anaerobically in $1.0 \mathrm{ml}$ of the medium in stoppered reaction tubes for $3 \circ \mathrm{min}$ at $37^{\circ}$. The incubation medium contained the following at the concentration shown: potassium phosphate $\mathrm{pH} 7 \cdot 6$ (5 mmol), $\mathrm{KHCO}_{3}(50 \mathrm{mmol}), \operatorname{ATP}(2.5 \mathrm{mmol}), \mathrm{NAD}(0.5 \mathrm{mmol})$, nicotinamide (40 $\mathrm{mmol}), \mathrm{MgSO}_{4}(4 \mathrm{mmol})$, cysteine hydrochloride ( $\mathrm{x} \mathrm{mmol}$ ), and one of the following substrates at a concentration of ro $\mathrm{mmol}$-glucose, glucose-6-phosphate, fructose r-6-diphosphate or phosphoenolpyruvate. For to min before and during the period of incubation, the tubes were gassed continuously with a mixture of $95 \% \mathrm{~N}$ and $5 \% \mathrm{CO}_{2}$. The reaction was started by the addition of the homogenate, and stopped by adding $0.5 \mathrm{ml} 6 \%(\mathrm{w} / \mathrm{v})$ perchloric acid. The mixture was centrifuged to remove protein and the supernatant fraction neutralized with $5 \mathrm{M}-\mathrm{K}_{2} \mathrm{CO}_{3}$. Lactate was measured in the supernatant fraction after precipitation of perchlorate.

Insulin sensitivity. An intravenous infusion was started into a peripheral vein, and $0.4 \mathrm{~g}$ glucose $/ \mathrm{kg}$ body-weight was injected. Serial blood samples were collected from a heel-prick for estimation of glucose. A second similar intravenous injection of glucose was given $\mathrm{I} h$ after the first and was immediately followed by intravenous injection of 0.1 unit soluble insulin $/ \mathrm{kg}$ body-weight. Serial heel-prick samples were then taken over a period of $30 \mathrm{~min}$ for estimation of glucose. At the end of the study a further injection of glucose was given to obviate any possibility of hypoglycaemia.

Effect of diet on glucose tolerance and insulin sensitivity. Recovered children were usually studied when they had been on a relatively high-fat diet, since it is our 
Table 2. Glucose, lactate and pyruvate concentrations in blood of malnourished and recovered children after intravenous injection of glucose

(Mean values with their standard errors; numbers of children in parentheses)

\begin{tabular}{|c|c|c|c|c|c|c|c|c|}
\hline \multirow{2}{*}{$\begin{array}{l}\text { Time after } \\
\text { injection }(\mathrm{min}) . .\end{array}$} & \multicolumn{4}{|c|}{ Malnourished (7) } & \multicolumn{4}{|c|}{ Recovered (8) } \\
\hline & 0 & I5 & 30 & 60 & 0 & I 5 & 30 & 60 \\
\hline $\begin{array}{l}\text { Glucose } \\
(\mathrm{mg} / 100 \mathrm{ml})\end{array}$ & $\begin{array}{r}52 \cdot 8 \\
\pm 2 \cdot 3\end{array}$ & $\begin{array}{r}144 \cdot 9 \\
\pm 2 I \cdot 2\end{array}$ & $\begin{array}{r}118.8 \\
\pm 14.2\end{array}$ & $\begin{array}{r}69 \cdot 9 \\
+16.6\end{array}$ & $\begin{array}{r}75.5 \\
\pm 2.9\end{array}$ & $\begin{array}{r}187 \cdot 3 \\
\pm 19 \cdot 3\end{array}$ & $\begin{array}{l}120.4 \\
\pm 7.1\end{array}$ & $\begin{array}{r}78 \cdot 7 \\
\pm 3 \cdot 0\end{array}$ \\
\hline $\begin{array}{l}\text { Pyruvate } \\
(\mu \mathrm{mol} / 100 \mathrm{ml})\end{array}$ & $\begin{array}{r}10.3 \\
\pm 1 \cdot 3\end{array}$ & $\begin{array}{r}13 \cdot 2 \\
\pm 2 \cdot 2\end{array}$ & $\begin{array}{r}12 \cdot 5 \\
\pm 1 \cdot 3\end{array}$ & $\begin{array}{r}9 \cdot 5 \\
\pm \mathrm{I} \cdot \mathrm{r}\end{array}$ & $\begin{array}{r}79 \\
\pm 0.3\end{array}$ & $\begin{array}{r}10.2 \\
\pm 0.8\end{array}$ & $\begin{array}{r}12.1 \\
\pm 0.8\end{array}$ & $\begin{array}{r}10.0 \\
\pm 0.8\end{array}$ \\
\hline $\begin{array}{l}\text { Lactate* } \\
(\mu \mathrm{mol} / \mathrm{r} 00 \mathrm{ml})\end{array}$ & $\begin{array}{r}178.6 \\
\pm 22.6\end{array}$ & $\begin{array}{r}140 \cdot 0 \\
\pm 27 \cdot 3\end{array}$ & $\begin{array}{r}14 r \cdot 0 \\
\pm 20.7\end{array}$ & $\begin{array}{r}14 I \cdot O \\
\pm 14 \cdot I\end{array}$ & $\begin{array}{r}104.3 \\
\pm 22.6\end{array}$ & $\begin{array}{r}\overline{147 \cdot 6} \\
\pm 46 \cdot 1\end{array}$ & $\begin{array}{r}149 \cdot 5 \\
\pm 27 \cdot 3\end{array}$ & $\begin{array}{r}I 3 I \cdot 6 \\
\pm I 4 \cdot I\end{array}$ \\
\hline
\end{tabular}

standard practice to feed children recovering from malnutrition on a high-calorie diet in which the bulk of the calories is derived from fat. In a group of children some tests were repeated after $7^{-10} \mathrm{~d}$ on an isocaloric low-fat diet in which the carbohydrate was given mainly as sucrose. The compositions of the two types of diet are shown in Table I. In this study, the pre-injection and 4 min post-injection samples were obtained by venepuncture and plasma insulin was measured in addition to blood glucose. Subsequent samples were taken by heel-prick.

Analyses. Glucose was measured by the glucose oxidase method of Huggett \& Nixon (1957). Lactate and pyruvate in blood were measured by standard enzymic spectrophotometric assays (Bergmeyer, $x_{965}$ ). Lactate from the muscle homogenate studies was also assayed enzymically, but the NAD to NADH change was measured fluorimetrically. Standard solutions of zinc lactate were assayed with every lot of determinations. Net lactate production represents the difference between lactate produced without substrate and that produced in the presence of substrate.

Glucose disappearance rates after intravenous injection of glucose were measured by plotting the actual blood glucose values on semi-logarithmic paper and measuring the half-time of disappearance from the line of best fit assigned to the points by inspection. It was assumed that glucose disappearance follows first-order kinetics and the $\mathrm{K}$ value, or percentage of the substance which disappears from the pool per min is given by $\left(0.693 / t_{0.5(\mathrm{~min})}\right) \times 100$. The $\mathrm{K}$ values without or with insulin are referred to as $\mathrm{K}_{\mathrm{G}}$ or $\mathrm{K}_{\mathrm{G}+\mathrm{I}}$. Protein was measured by the method of Lowry, Rosebrough, Farr \& Randall (I95I).

\section{RESULTS}

The fasting blood glucose, lactate and pyruvate concentrations for the malnourished and recovered children and the values obtained after intravenous glucose injection are shown in Table 2 . Initially there was a significant $(P<0.00 \mathrm{r})$ hypoglycaemia in the malnourished children, but there was no difference in blood pyruvate concentrations between the two groups. Blood pyruvate concentrations rose both in the malnourished and recovered children. After intravenous glucose injection, blood lactate fell in the malnourished children, but in those who had recovered there was a definite 


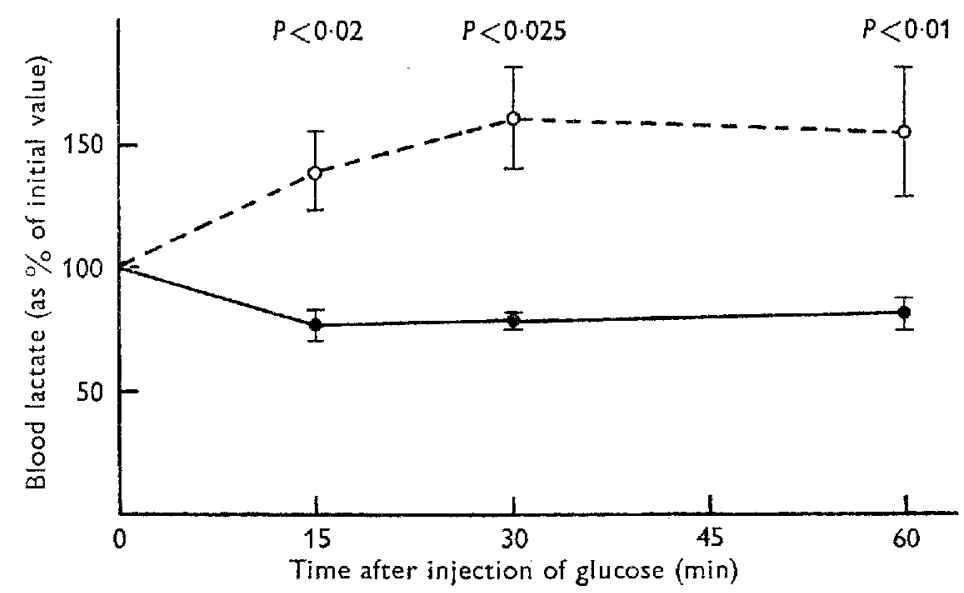

Fig. I. The change in blood lactate after intravenous injection of glucose in malnourished (e) and recovered children (O). Values are means and standard errors. The significance of the differences between the mean values is also given.

Table 3. Lactate production ( $\mu$ mollg alkali-soluble protein per 30 min) 'in vitro' by muscle homogenates of malnourished, recovered and normal children

(Mean values with their standard errors; numbers of children in parentheses)

Substrate

None

Glucose

Glucose-6-phosphate

Fructose-I-6-diphosphate

Phosphoenolpyruvate
Malnourished (

$$
88 \pm \text { I I }
$$

$91 \pm 10$

I $95 \pm 37$

$166 \pm 18$

I IO \pm I 4
8) Recovered (8)

$96 \pm 16$

$97 \pm 16$

$179 \pm 28$

$188 \pm 22$

$\mathrm{I} 2 \mathrm{I} \pm \mathrm{I} 4$
Normal ( 7 )

$79 \pm 13$

$77 \pm 8$

$425 \pm 59$

$361 \pm 84$

$126 \pm 18$

Table 4 . Glucose disappearance rates without $\left(K_{G}\right)$ and with $\left(K_{G+I}\right)$ insulin injection in malnourished and recovered children

(Mean values with their standard errors; numbers of children in parentheses)

$\begin{array}{lccc} & & \begin{array}{c}\text { Significance } \\ \text { of difference } \\ P\end{array} \\ \mathrm{~K}_{\mathrm{a}} & \text { Malnourished (xx) } & \text { Recovered (I 5) } & <0.005 \\ \mathrm{~K}_{\mathrm{G}+1} & \mathrm{I} \cdot 96 \pm 0.22 & 2.99 \pm 0.19 & <0.0025\end{array}$

rise. Fasting blood lactate values were measured in a further three malnourished and three recovered children. The mean values were $157 \pm 22 \mu \mathrm{mol} / 100 \mathrm{ml}(n=7)$ for the malnourished, and $124 \pm 19(n=\mathrm{II})$ for the recovered. There was no significant difference between these two values. Because of the wide scatter of lactate values they are all expressed as percentages of the initial values and the result is shown in Fig. I. There was a significant sustained rise in the recovered children while the converse was seen in the malnourished. The significance of the differences between the means at $\mathrm{I} 5,30$ and $60 \mathrm{~min}$ was $P<0.02,<0.025,<0.01$.

Lactate production by muscle homogenates is shown in Table 3. There was no difference in lactate production from any of the substrates when malnourished children are compared with the recovered ones. When comparison is made with normal children, 


\section{Table 5. Effect of a high-fat or a low-fat diet on carbohydrate tolerance in children}

(Mean values with their standard errors for six children)

\begin{tabular}{|c|c|c|}
\hline & High-fat & Low-fat \\
\hline Fasting blood glucose $(\mathrm{mg} / 100 \mathrm{ml})$ & $84 \cdot 5 \pm 5 \cdot 5$ & $79 \cdot 3 \pm 5 \cdot 8$ \\
\hline Fasting insulin $(\mu \mathrm{U} / \mathrm{ml})$ & $8 \cdot 4 \pm 0 \cdot 6$ & $7 \cdot 4 \pm 0.2$ \\
\hline Peak glucose (4 min) & $246 \cdot 9 \pm 7 \cdot 0$ & $228 \cdot 7 \pm I x \cdot 4$ \\
\hline Peak insulin ( $4 \mathrm{~min})$ & $27 \cdot 6 \pm 2 \cdot 4$ & $28 \cdot 6 \pm 5 \cdot 3$ \\
\hline $\mathrm{K}_{\mathrm{a}}$ & $2.03 \pm 0.17$ & $2.48 \pm 0.27$ \\
\hline $\mathrm{K}_{\mathrm{G}+1}$ & $5.13 \pm 0.43$ & $5 \cdot 68 \pm 0.39$ \\
\hline
\end{tabular}

$K_{G}$ and $K_{G+1}$, glucose disappearance rate, without and with insulin injection.

there was a significant difference when glucose-6-phosphate or fructose $1-6$-diphosphate was used as substrate.

The results of the glucose disappearance rates with and without insulin are shown in Table 4 . The $K_{G}$ and the $K_{G+I}$ were both significantly lower in the malnourished child.

The results for the glucose tolerance tests and insulin sensitivity as affected by the composition of the diet are shown in Table $5 . \mathrm{K}_{\mathrm{G}}$ and $\mathrm{K}_{\mathrm{G}+\mathrm{I}}$ were the same for the children on either diet. The fasting blood sugar, plasma insulin, as well as the insulin response $4 \mathrm{~min}$ after intravenous glucose injection were the same with both diets.

\section{DISCUSSION}

The two major possibilities which must be considered in relation to the impairment of glucose tolerance in malnutrition are a primary $\beta$-cell defect, whereby there is poor insulin release in response to a stimulus, or failure of the peripheral tissues to metabolize glucose, perhaps as a result of insensitivity to the insulin released. As mentioned above, several studies have now shown that insulin release from the pancreas is impaired in malnutrition (Baig \& Edozien, I 965 ; James \& Coore, I $970 ;$ Graham, Cordano, Blizzard \& Cheek, r969; Milner, 1971). The cause of this is not clear. Is it a result of temporary structural damage to the $\beta$-cell by malnutrition, or interruption of a metabolic sequence necessary for the stimulation of insulin release?

Morbid anatomical studies all show striking changes in the pancreas from malnourished children (Davies, I948; Gillman \& Gillman, I951). Bras, Waterlow \& DePass (I956) emphasized the relationship between fatty change in the liver and fatty change in the pancreas, but they also showed that, in malnourished children who died but did not have a fatty liver, there was also a strong association between malnutrition and pancreatic pathology. As far as we are aware, there are no reports of the ultrastructural changes in the pancreas of malnourished children or experimental animals, and it is not clear whether the damage resulting from malnutrition affects both the acinar and islet cells.

Our first study shows that there is impaired peripheral glycolysis if changes in blood lactate can be taken as indicating anaerobic metabolism of glucose. In the 
recovered children there was a significant rise in blood lactate, whereas in the malnourished group lactate concentrations tended to fall. A possibility to be considered is that the spaces of distribution of lactate were different in the two groups of children, but when the lactates are expressed as a percentage change from the initial value it is even clearer that there was a true rise in concentrations in the recovered but not in the malnourished children. Similar results have been obtained from Chile where Oxman, Maccioni, Zuniga, Spada \& Mönckeberg (1968) studied normal and marasmic children and found that intravenous injection of glucose was followed by a rise in blood pyruvate and lactate in normal children but that in the marasmics there was a fall. There was also a marked glucose intolerance in the marasmic infants. Neither our findings nor any studies in vivo allow us to state whether there is impaired entry of glucose into the cell or a block at one of the steps in the glycolytic pathway. A lack of insulin could obviously lead to the former, but it is of interest that Metcoff, Frenk, Yoshida Pinedo, Kaiser \& Hansen ( 1966 ) have postulated that in muscle samples from malnourished infants there is a reduction in pyruvate kinase activity which may be related to the altered intracellular ionic composition.

Instead of studying individual enzymes of glycolysis, it was decided to test the ability of a whole muscle homogenate to metabolize various substrates. This method has been used successfully to demonstrate a deficiency of muscle phosphofructokinase in a human subject (Layzer $e t$ al. ${ }^{1967}$ ). The failure to detect any difference between the muscle homogenates from the malnourished and recovered children would suggest that any impairment of glucose utilization was not caused by any specific enzymic defect in muscle. If the same pattern exists in other tissues, this might indicate that the cause of the glucose intolerance lies at the level of entry of glucose into the cell - a reflection of low insulin levels or relative insulin insensitivity. Another possibility worth considering is that there is a quantitative reduction in those tissues which normally metabolize glucose, i.e. an altered body composition as a cause of impaired glucose tolerance. It would be of interest to compare glucose disappearance rates in relation to some measure of lean body mass such as total body potassium or $24 \mathrm{~h}$ urinary creatinine.

There was a striking difference in the behaviour of muscle homogenates from normal children and those from children who were or had been malnourished. This is of special interest in view of the persistence of glucose intolerance after clinical recovery. It could be that there are two mechanisms for the glucose intolerance of malnutrition: one related to impaired entry of glucose into the cell or simply a smaller mass of tissues utilizing glucose, and the other which persists after recovery related to a relative block in glycolysis. From our findings in vitro such a block would lie distal to the formation of triosephosphate.

Potassium deficiency must be considered among the reasons for the glucose intolerance of malnutrition. It has been well established that malnourished infants may be severely potassium-depleted with very low concentrations of total body and muscle potassium (Hansen, 1956; Waterlow \& Mendes, 1957; Metcoff et al. r966; Garrow, 1965; Nichols, Alleyne, Barnes \& Hazlewood, 1969; Alleyne, Millward \& Scullard, 1970); and potassium depletion much less severe than that encountered in malnutrition 
has produced glucose intolerance in men and experimental animals (Saglid, Andersen \& Andreasen, I96r; Mondon, Burton, Grodsky \& Ishida, r968). There have been as yet, however, no studies in which glucose tolerance and body potassium status are assessed simultaneously.

The sensitivity of the peripheral tissues to exogenous insulin was tested to determine if this could be the cause of the glucose intolerance. Ideally, sensitivity to insulin should be tested by simply injecting insulin and noting the rate of fall of blood sugar. Valuable information could also be obtained from noting the rate of recovery of the blood sugar to normal values. This was felt to be dangerous in these children not only because they were already relatively hypoglycaemic but also because it has been our experience that dangerous levels of hypoglycaemia may occur in malnutrition in the absence of the usual clinical signs. Hence constant monitoring with a method providing rapid estimations of blood glucose would have been necessary.

Heard \& Turner $(1967)$ and Heard \& Henry (1969) have used the rate of disappearance of glucose after glucose plus insulin $\left(\mathrm{K}_{\mathbf{G}+\mathrm{I}}\right)$ as their measure of insulin sensitivity in pigs and dogs and have shown that $\mathrm{K}_{\mathrm{G}}$ is closely related to $\mathrm{K}_{\mathrm{G}+\mathrm{I}}$. There is an increase of both with age. In our malnourished children $\mathrm{K}_{G}$ and $\mathrm{K}_{\mathrm{G}+\mathrm{I}}$ were depressed indicating perhaps that there was peripheral insulin insensitivity to which the low $\mathrm{K}_{G}$ might be attributable. Thus it would seem that, in addition to the previously described poor output of insulin in response to a glucose load, there is in addition some insulin insensitivity. Heard \& Turner (1967) have also demonstrated a reduction in $\mathrm{K}_{G}$ and $\mathrm{K}_{\mathrm{G}+\mathrm{I}}$ in dogs fed on low-protein diets.

In a preliminary account of this work (Alleyne, Flores, Trust \& Waterlow, 1970) we had used the ratio of $\mathrm{K}_{G+\mathrm{I}}$ to $\mathrm{K}_{G}$ as a better index of insulin sensitivity and, since when one compares this ratio in malnourished and recovered children there is no difference, we had concluded that there was no insulin insensitivity in malnutrition. Though there are still reservations about the unqualified use of the $\mathrm{K}_{\mathrm{G}+\mathrm{I}}$ as a measure of insulin sensitivity, we now think that it is perhaps preferable to the ratio and indicates some insulin insensitivity in malnutrition. It would have been ideal to have insulin concentrations both when $\mathrm{K}_{\mathrm{G}}$ and $\mathrm{K}_{\mathrm{G}+\mathrm{I}}$ were measured, since it is possible that injection of 0.1 unit $/ \mathrm{kg}$ body-weight in the malnourished child results in lower plasma concentrations of insulin because of a larger space of distribution of the insulin.

Glucose tolerance, fasting plasma insulin, insulin sensitivity and insulin response to glucose appear to have been uninfluenced by diet in the recovered children. It is, therefore, not possible to invoke diet as the cause of the relative impairment of glucose tolerance and insulin release when children who were fully recovered were compared with normal infants (James \& Coore, I970). We were unable to test any children who had never previously been malnourished.

There is no information in the literature on the effect of a high-fat diet on glucose metabolism in infants, but high-fat diets given to weanling rats cause hyperglycaemia, low concentrations of plasma insulin and impair the sensitivity of the peripheral tissues to insulin (Blázquez \& Lopez Quijada, 1968; Zaragoza \& Felber, 1970). All our children were tested first on the high-fat diet and then on the low-fat diet. It is 
possible that a period longer than Io $\mathrm{d}$ on the low-fat diet would have been necessary before significant changes appeared.

Our conclusion at this stage is that the glucose intolerance of malnutrition is related both to the low output of insulin in response to glucose and some peripheral insensitivity to insulin. Persistent glucose intolerance after recovery from malnutrition may be related to a block in glycolysis. There is no apparent effect of dietary fat on insulin release, glucose tolerance or insulin sensitivity in children recovered from malnutrition.

\section{REFERENCES}

Alleyne, G. A. O. (1970). W. Indian med. F. 19, 32.

Alleyne, G. A. O., Flores, H., Trust. P. M. \& Waterlow, J. C. (1970). F. Physiol, Lond. 213, 30 P.

Alleyne, G. A. O., Millward, D. J. \& Scullard, G. H. (1970). F. Pediat. 76, 75.

Baig, H. A. \& Edozien, J. C. (I965). Lancet ii, 662 .

Bergmeyer, H. U. (1965). Methods of Enzymatic Analysis. New York: Academic Press.

Blázquez, E. \& Lopez Quijada, E. (I968). F. Endocr. 42, 489.

Bras, G., Waterlow, J. C. \& DePass, E. (1956). F. trop. Pediat. 2, 147.

Cook, G. G. (1 967). Nature, Lond. 215, 1295.

Davies, J. N. P. (I948). Lancet i, 3 I7.

Garrow, J. S. (1965). Lancet ii, 455 .

Gillman, J. \& Gillman, 'T. (I95 I). Perspectives in Human Malnutrition. New York; Grune and Stratton.

Graham, C. G., Cordano, A., Blizzard, R. M. \& Cheek, D. B. (I969). Pediat. Res. 3, 579.

Hadden, D. R. (1967). Lancet ii, 589.

Hansen, J. D. L. (1956). S. Afr. F. Lab. clin. Med. 2, 206.

Heard, C. R. C. \& Henry, P. A. J. (1 969). Clin. Sci. 37, 37.

Heard, C. R. C. \& Turner, M. R. (I967). Diabetes $16,96$.

Huggett, A. St G. \& Nixon, D. A. (I957), Lancet ii, 368 .

James, W. P. T. \& Coore, G. H. (1970). Am. F. clin. Nutr. 23, 386.

Layzer, R. B., Rowland, L. P. \& Ranney, H. M. (1967). Archs Neurol., Chicago 17, 5 I2.

Lowry, O. H., Rosebrough, N. J., Farr, A. L. \& Randall, R. J. (1951). F. biol. Chem. 193, 265.

Metcoff, J., Frenk, S., Yoshida, T., Pinedo, R. T., Kaiser, E. \& Hansen, J. D. L. (1966). Medicine, Baltimare 45, 365 .

Milner, R. D. G. (1971). Pediat. Res. 5, 33.

Mondon, C. E., Burton, S. D., Grodsky, G. M. \& Ishida, T. (I968). Am. F. Physiol. 215, 779.

Nelson, W. E. (1959). Textbook of Pediatrics. Philadelphia and London: W. B. Saunders Co.

Nichols, B. L., Alleyne, G. A. O., Barnes, D. J. \& Hazlewood, C. F. (1969). Pediatrics, Springfield 74, 49 .

Nichols, B. L., Hazlewood, C. F. \& Barnes, D. J. (1968). F. Pediat. 72, 840.

Oxman, S. V., Maccioni, A. S., Zuniga, A. C., Spada, R. G. \& Mönckeberg, F. B. (I968). Am. $\mathcal{F}$. clin. Nutr, 21, 1285 .

Saglid, U., Andersen, V. \& Andreasen, P. B. (т96r). Acta med. scand. r69, 243.

Sloane, D., Taitz, L. S. \& Gilchrist, G. S. (I96I). Br. med. 7. I, 32.

Waterlow, J. C., Cravioto, J. \& Stephen, J. M. L. (x960). Adv. Protein Chem. 15, I31.

Waterlow, J. C. \& Mendes, C. B. (1957). Nature, Lond. 18o, 1361.

Zaragoza, N. \& Felber, J. P. (1970). Horm. Metab. Res. 2, 323. 